\title{
A kirromycin-resistant EF-Tu species reverses streptomycin dependence of Escherichia coli strains mutated in ribosomal protein $\mathrm{S} 12$
}

\author{
Anne-Marie Zuurmond, Leo A. H. Zeef $†$ and Barend Kraal \\ Author for correspondence: B. Kraal. Tel: +31715274770 Fax: +31715274340. \\ e-mail: B.Kraal@chem.leidenuniv.nl
}

Leiden Institute of Chemistry, Department of Biochemistry, Leiden University, PO Box 9502, 2300 RA Leiden, The Netherlands

\begin{abstract}
Streptomycin dependence can be caused by mutations in ribosomal protein S12. Mutations suppressing such streptomycin dependence have been found in ribosomal proteins S4 and 55, and in 16S rRNA. Here a new suppressor mutation localized in elongation factor Tu (EF-Tu) is described, consistent with recent models of ribosome-EF-Tu-tRNA interaction at the decoding centre. The EF-Tu mutation was obtained by genetic selection for streptomycin independence; it was identified as Ala375 $\rightarrow$ Thr, previously described as EFTuA $_{R}$ and known to confer a kirromycin-resistant, error-prone phenotype. Also, other streptomycin-dependent (SmD) S12 mutations could be complemented by this mutation. The streptomycin-independent ( $\left(\mathrm{Sm}^{\prime}\right)$ strain grows more slowly than the wild-type (wt), suggesting that not all the defects of the S12 mutation can be complemented by EF-Tu[A375T]. Moreover, this strain is more susceptible than wt to reduction in the cellular EF-Tu concentration, and disruption of tufB led to considerable growth-rate impairment. Expression of EF-Tu from tufB, not only of wt EF-Tu and EF-Tu[A375T] but, remarkably, also of EF-Tu[G222D], known as EF-TuB ${ }_{0}$ and defective in protein synthesis, equally contributed to cell growth. In vitro analysis revealed a decreased translational activity of wt EF-Tu with $\mathrm{Sm}^{\mathrm{D}}$ ribosomes as compared to EF-Tu[A375T], while EF-Tu[G222D] showed no activity at all, just as with wt ribosomes. Possible mechanisms are discussed for the improved growth rate observed in such Sm' strains when they include wt EF-Tu or EF-Tu[G222D].
\end{abstract}

Keywords: elongation factor Tu, error-prone mutations, $r p s L$, translational accuracy

\section{INTRODUCTION}

One of the key components in protein biosynthesis in Escherichia coli is the elongation factor Tu (EF-Tu), encoded by two almost identical genes, tufA and tufB. It is a member of the GTPase superfamily and complexes aminoacyl-tRNA (aa-tRNA) in the GTP-bound state. The ternary complex formed binds to a programmed ribosomal A-site and after correct codon-anticodon recognition GTP is hydrolysed, followed by the release

\footnotetext{
†Present address: John Innes Centre, Colney Lane, Norwich NR4 7UH, UK. Abbreviations: aa-tRNA, aminoacyl-tRNA; EF-Tu, elongation factor Tu; $\mathrm{EF}^{-T U A_{S}}$ or EF-TUB $\mathrm{B}_{S}$, wild-type EF-Tu from tufA or tufB, respectively; EF-TUA or EF-TUB ${ }_{R}, E F-T u[A 375 T]$ from tufA or tufB, respectively; EF-TuB ${ }_{0}$, EFTu[G222D] from tufB; $\mathrm{Sm}^{\mathrm{D}}, \mathrm{Sm}^{\prime}, \mathrm{Sm}^{\mathrm{R}}$ or $\mathrm{Sm}^{\mathrm{S}}$, streptomycin-dependent, independent, -resistant or -sensitive; $\mathrm{Tc}^{\mathrm{R}}$, tetracycline-resistant; $w t$, wildtype.
}

of EF-Tu · GDP from the ribosome (Miller \& Weissbach, 1977). The EF-Tu binding site at the ribosomal A-site is located on both subunits. On the $30 \mathrm{~S}$ subunit it is in the vicinity of ribosomal proteins $\mathrm{S} 4, \mathrm{~S} 5$ and $\mathrm{S} 12$, and the 530 loop of $16 \mathrm{~S}$ rRNA. On the $50 \mathrm{~S}$ subunit it is close to ribosomal proteins $\mathrm{L} 10$ and L11, the L7/L12 stalk, the $\alpha$-sarcin stem-loop structure and the thiostrepton binding structure of 23S rRNA (Saarma et al., 1997; Stark et al., 1997 and references therein). The interplay between EF-Tu and these ribosomal components controls translational accuracy during protein synthesis.

The antibiotic streptomycin interferes with the translation process by inducing misreading. Footprinting studies have shown that streptomycin binds to $16 \mathrm{~S}$ rRNA at the A-site region of the decoding centre (Spickler et al., 1997). Resistance to streptomycin can be obtained by mutations in $16 \mathrm{~S}$ rRNA (Powers \& Noller, 
1991 and references therein), but also by mutations in ribosomal protein S12 (Ozaki et al., 1969). Streptomycin-resistant $\left(\mathrm{Sm}^{\mathrm{R}}\right)$ mutations in $\mathrm{S} 12$ (encoded by $r p s L$ ) can lead to hyperaccuracy and decreased activity in protein synthesis, and even to dependence on the error-inducer streptomycin (Birge \& Kurland, 1969). These streptomycin-dependent $\left(\mathrm{Sm}^{\mathrm{D}}\right)$ mutations are clustered in two regions, one spanning codons 40-43, the other 87-93 (Timms et al., 1992). The $\mathrm{Sm}^{\mathrm{D}}$ phenotype is not caused by hyperaccuracy alone since some of the $S m^{R}$ mutants that do not require streptomycin are more error-restrictive than $\mathrm{Sm}^{\mathrm{D}}$ mutants (Ruusala et al., 1984; Andersson et al., 1986). Quench-flow analysis has shown that $\mathrm{Sm}^{\mathrm{D}}$ ribosomes, in addition to the defects they have in common with $S \mathrm{~m}^{\mathrm{R}}$ ribosomes, are perturbed in a step between peptidyl transfer and translocation or after translocation and before binding a new ternary complex (Bilgin et al., 1992).

Streptomycin dependence can also be generated in other ways, for example by (i) combining a hyperaccurate $\mathrm{Sm}^{\mathrm{R}} \mathrm{S} 12$ mutation with the $1491 \mathrm{C}$ mutation in $16 \mathrm{~S}$ rRNA (causing a paromomycin-resistant and slowgrowth phenotype) (O'Connor et al., 1991), (ii) combining a hyperaccurate $\mathrm{Sm}^{\mathrm{R}} \mathrm{S} 12$ mutation with a miaA mutation (causing a defect in a tRNA modification enzyme which reduces the efficiency of UAG/UGA readthrough) (Petrullo et al., 1983), or (iii) combining a pseudodependent S12 mutant with the error-restrictive 2661C mutation in 23S rRNA (Bilgin \& Ehrenberg, 1994).

Streptomycin dependence of S12 mutants can be suppressed by ram (ribosomal ambiguity) mutations in ribosomal proteins S4 and S5, and in $16 \mathrm{~S}$ rRNA (Birge \& Kurland, 1970; Deuser et al., 1970; Allen \& Noller, 1991; Lodmell \& Dahlberg, 1997). In the absence of the $\mathrm{Sm}^{\mathrm{D}} \mathrm{S} 12$ mutation these ram mutations cause a phenotype of high-level misreading.

Translational accuracy can also be affected by mutant EF-Tus, such as kirromycin-resistant EF-TuA $A_{R}$ (A375T), EF-TuA* (later identified as Q124K) and the null mutant $\mathrm{EF}^{-T u B_{0}}(\mathrm{G} 222 \mathrm{D})$, which were originally found in kirromycin-resistant strains (Duisterwinkel et al., 1981, 1984; Zeef \& Bosch, 1993) and promote frameshifting (Hughes et al., 1987; Vijgenboom \& Bosch, 1989). The subscripts in $A_{R}$ and $B_{0}$ refer to their effect on the kirromycin phenotype, i.e. sensitive for wild-type (wt) cells with EF-TuA and EF-TuB (for $_{\mathrm{S}}$ further explanation, see van der Meide \& Vijgenboom, 1981). When EF-TuA $A_{R}$ or EF-TuA* is combined with EF-TuB ${ }_{0}$, the frequency of frameshifting exceeds the sum of the separate contributions (Vijgenboom \& Bosch, 1989). Such a synergistic effect between EF-TuA $A_{R}$ and $\mathrm{EF}-\mathrm{TuB}_{0}$ has also been observed for nonsense suppression (Vijgenboom et al., 1985). The increase in frameshifting and nonsense suppression caused by EF$\mathrm{TuB}_{0}$ is striking because this mutant species by itself is not active in protein synthesis (Swart et al., 1987; Talens et al., 1996).

Since EF-Tu, together with other ribosomal components, is involved in maintaining translational ac- curacy and binds in the vicinity of $\$ 12$ at the ribosome, we tried to find mutations in EF-Tu that were able to suppress streptomycin dependence of S12 mutants. We found that the above-mentioned error-prone EF-TuA $\mathrm{A}_{\mathrm{R}}$ mutation can also cause suppression of streptomycin dependence. This mutation has been reported to complement growth defects of hyperaccurate $\mathrm{Sm}^{\mathrm{R}} \mathrm{S} 12$ mutants (Tapio \& Isaksson, 1988; Tubulekas \& Hughes, 1993).

\section{METHODS}

Strains, media and genetic procedures. The E. coli strains used in this study are listed in Table 1 . The chromosomal tuf genes (tufA and $t u f B$ ) of $\mathrm{Sm}^{\mathrm{D}}$ strain UD666 (harbouring the rpsL666 allele) were subjected to random mutagenesis by M13-mediated allelic replacement (Zeef \& Bosch, 1993). A tetracycline-resistant $\left(\mathrm{Tc}^{\mathrm{R}}\right)$ gene linked to the tuf gene on the M13 phage (M13mp9Zam20C) enables selection for integration of the phage into the host genome by homologous recombination with one of the two tuf genes. The following deviations from the standard protocol were made. M13 lysogens were formed in medium containing $50 \mu \mathrm{g}$ streptomycin $\mathrm{ml}^{-1}$, followed by incubation at $37^{\circ} \mathrm{C}$ for $2 \mathrm{~h}$ after removal of the unadsorbed phages. Selection for streptomycinindependent $\left(\mathrm{Sm}^{\mathrm{T}}\right)$ strains was on LC plates (Zeef \& Bosch, 1993) containing $50 \mu \mathrm{g}$ tetracycline $\mathrm{ml}^{-1}$ and lacking streptomycin. To identify the $t u$ f mutation in the $\mathrm{Sm}^{1}$ strain LZ18L, M13 retrieval was performed. Since retrieval of the mutation would make the strain $\mathrm{Sm}^{\mathrm{D}}$ again, strain LZ18L was first transformed with plasmid pNO1523 (encoding wt S12) (Dean, 1981), which improves the growth rate of this strain, but more importantly makes an $\mathrm{Sm}^{\mathrm{D}}$ strain sensitive to streptomycin. The mutation was identified by sequencing the retrieved M13 using T7 DNA polymerase (Pharmacia), $\left[\alpha^{3}{ }^{32} \mathrm{P}\right] \mathrm{dCTP}$ (ICN) and $t u f$ primers (Zeef \& Bosch, 1993).

The transducing bacteriophage P1 was used for all transductional crosses (Miller, 1972). Transformation of strain LZ18L with plasmid pNO1523 also facilitated the preparation of a P1 lysate from this strain. This P1 lysate was used to determine which $t u f$ gene was mutated in LZ18L by infecting the fusidic-acid-resistant strain LBE2040 $\left(\mathrm{A}_{\mathrm{s}} \mathrm{B}_{\mathrm{s}} f u s\right)$ and selecting for tetracycline resistance. A high frequency of transductants showed co-transduction of fusidic acid sensitivity, indicating that the $T c^{\mathrm{R}}$ gene was linked to the sensitive fus gene of LZ18L, which is located upstream of $t u f A$ in the $s t r$ operon. After identification of the tufA mutation, the same P1 lysate was used to simultaneously transduce rpsL666 tuf $A_{\mathrm{R}}$ (a $90 \%$ linkage exists between these two genes) to strains LBE2041, EV102, LBE2020 and PM505 to obtain the isogenic strains, AZ25L, AZ27L, AZ29L and AZ31L, respectively, differing only in their $t u f B$ allele. The strains used were (1) selected for tetracycline resistance, because the $\mathrm{Tc}^{\mathrm{R}}$ gene is linked to $t u f A_{\mathrm{R}}$ in LZ18L, and (2) screened for small colonies, because strains harbouring rpsL666 and $t u f A_{\mathrm{R}}$ grow more slowly than strains harbouring only tuf $A_{\mathrm{R}}$. Strain AZ1 was constructed by transducing UA254 (miaA) with a P1 lysate of UA244 ( $r p s L 282$ ) and selecting for $\mathrm{Sm}^{\mathrm{D}}$ colonies on LC plates containing $100 \mu \mathrm{g}$ streptomycin $\mathrm{ml}^{-1}$. Screening for kirromycin resistance was done on plates containing $1.5 \mathrm{mM}$ EDTA $(\mathrm{pH} 8.0)$ and $100 \mu \mathrm{g}$ kirromycin $\mathrm{ml}^{-1}$. Kirromycin was a generous gift from Gist-Brocades.

Growth rates were determined at $37^{\circ} \mathrm{C}$ in $10 \mathrm{ml}$ liquid LC medium by measuring the time required for a doubling of the $\mathrm{OD}_{560}$ during exponential growth phase. Cultures were grown 
Table 1. E. coli strains used in this study

\begin{tabular}{|c|c|c|}
\hline Strain* & Genotype & Reference \\
\hline $\mathrm{AZ} 1$ & rpsL282 miaA rpoB valR gyrA thi trpT (Su9) pur ${ }^{+} \Delta$ (pro-lac) (F'lac pro $\left.\operatorname{Tn} 10 d c a t\right)$ & This work \\
\hline AZ25L & rpsL666† tufA $\ddagger$ sup ${ }^{\circ}$ rpoB (F'lac pro Tn10dcat) & This work \\
\hline AZ27L & rpsL666† tufA $A$ tufB $B \neq s u p^{\circ}$ rpoB (F'lac pro Tn10dcat) & This work \\
\hline AZ29L & rpsL666† tufA $\ddagger$ tufBS sup ${ }^{\circ}$ rpoB (F'lac pro $\left.\mathrm{Tn} 10 d c a t\right)$ & This work \\
\hline AZ31L & rpsL666† tufA tufB: : Mu sup ${ }^{\circ}$ rpoB (F'lac pro Tn10dcat) & This work \\
\hline CM1234 & rpsL827\|sup ${ }^{\circ}$ (F'lac pro Tn10dcat) & Timms \& Bridges (1993) \\
\hline CM1243 & rpsL8339 sup ${ }^{\circ}\left(\mathrm{F}^{\prime}\right.$ lac pro $\left.\mathrm{Tn} 10 \mathrm{dcat}\right)$ & Timms \& Bridges (1993) \\
\hline EV102 & tufB $\ddagger$ sup $p^{\circ}$ rpoB fus (F'lac pro Tn10dcat) & Vijgenboom \& Bosch (1987) \\
\hline LBE2020 & tufB $\ s u p^{0}$ rpoB (F'lac pro $\left.\mathrm{Tn} 10 d c a t\right)$ & Van der Meide et al. (1982) \\
\hline LBE2040 & $s u p^{\circ}$ fus & Van de Klundert et al. (1978) \\
\hline LBE2041 & $\sup ^{0}$ rpoB (F'lac pro Tn10dcat $)$ & Van de Klundert et al. (1978) \\
\hline LZ18L & rpsL666†tufA $\sup ^{\circ}$ (F'lac pro $\left.\mathrm{Tn} 10 \mathrm{dcat}\right)$ & This work \\
\hline LZ50 & rpsL666† tufB:: Mu sup ${ }^{\circ}$ rpoB (F'lac pro Tn10dcat) & This work \\
\hline LZ52L & 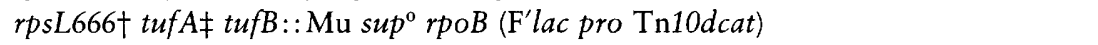 & This work \\
\hline PM505 & tufB:: Mu sup ${ }^{\circ}$ rpoB (F'lac pro Tn10dcat) & Van der Meide et al. (1982) \\
\hline UA244 & rpsL282 rpoB valR gyrA thi trpT (Su9) aro $^{+} \Delta($ pro-lac $)$ & Faxén et al. (1988) \\
\hline UA254 & miaA rpoB valR gyrA thi trpT (Su9) pur $r^{+} \Delta$ (pro-lac) (F'lac pro Tn10dcat) & Faxén et al. (1988) \\
\hline UD666 & rpsL666t sup ${ }^{\circ}$ & Ruusala et al. (1984) \\
\hline
\end{tabular}

"Strains that end with $\mathrm{L}$ are $\mathrm{Tc}^{\mathrm{R}} \mathrm{M} 13 \mathrm{mp} 9 \mathrm{Zam} 20 \mathrm{C}$ lysogens.

†The rpsL mutation is P90L.

$\ddagger$ The tuf mutation is A375T.

$\$$ The $t u f B$ mutation is G222D.

$\|$ The $r p s L$ mutation is $\mathrm{K} 42 \mathrm{Q}$.

I The rpsL mutation is $\mathrm{P} 90 \mathrm{R}$.

in $100 \mathrm{ml}$ flasks in a gyratory water-bath shaker (New Brunswick Scientific). The values in Table 2 are means of three independent measurements.

PCR and sequencing. For PCR amplification of chromosomal DNA from strains AZ25L, AZ27L, AZ29L, AZ31L and UD666, cells from a $10 \mathrm{ml}$ overnight culture were washed with $3 \mathrm{ml} \mathrm{H}_{2} \mathrm{O}$ and resuspended in $250 \mu \mathrm{H}_{2} \mathrm{O}$. The resuspended pellet was boiled for $10 \mathrm{~min}$ and the cell debris was pelleted at 13000 r.p.m. for $5 \mathrm{~min} ; 5 \mu \mathrm{l}$ of the supernatant was added to a mixture containing standard PCR buffer and primers. Pfu polymerase (Stratagene) was used to sustain the PCR reaction. The DNA oligonucleotides used for $r p s L$ amplification were Bio733 5' CCAGGAGCTCTTTAATGGCAACAG 3' (nt -14 to +10 of $r p s L$, creating a Sacl site) and Bio642 5' GGCGCACGTTTTCGAGAGCTACTT 3' (nt + 211 to +188 of $r p s G$, about 200 bp downstream of a BamHI site). The PCR product (about $700 \mathrm{bp}$ ) was digested with $\mathrm{Sacl}$ and $B a m \mathrm{HI}$ and cloned into pUC18. The rpsL fragment was sequenced by the dideoxy method using T7 DNA polymerase (Pharmacia) and $\left[\alpha^{32} \mathrm{P}\right] \mathrm{dCTP}(\mathrm{ICN})$.

Kirromycin band-shift assay. Strains were grown to an $\mathrm{OD}_{560}$ of 0.5 in $50 \mathrm{ml} \mathrm{LC}$ medium containing $50 \mu \mathrm{g}$ tetracycline $\mathrm{ml}^{-1}$. The cells were harvested, washed and resuspended in $500 \mu \mathrm{l}$ standard buffer $(50 \mathrm{mM}$ Tris $/ \mathrm{HCl}, \mathrm{pH} 7 \cdot 6,10 \mathrm{mM} \mathrm{MgCl}$, $40 \mathrm{mM} \mathrm{NH}_{4} \mathrm{Cl}, 1 \mathrm{mM}$ DTT). The cells were disrupted by sonication and the cell debris was removed at 13000 r.p.m. for $30 \mathrm{~min}$, yielding a cell-free extract. The ribosomes were subsequently removed by centrifugation of the cell-free extract at $100000 \mathrm{~g}$ in an Airfuge (Beckman) for $20 \mathrm{~min} ; 2.5 \mu \mathrm{l}$ of the ribosome-free extract was diluted in standard buffer with $10 \%(\mathrm{v} / \mathrm{v})$ glycerol in the presence or absence of $50 \mu \mathrm{M}$ kirromycin (final volume $25 \mu \mathrm{l}$ ) and incubated at $0^{\circ} \mathrm{C}$ for $10 \mathrm{~min}$. Samples of the reaction mixtures $(5 \mu \mathrm{l})$ were electrophoresed on a $12 \%(\mathrm{v} / \mathrm{v})$ non-denaturing polyacrylamide gel as described by Anborgh \& Parmeggiani (1991), blotted onto nitrocellulose and probed with antibodies raised against EFTu.

Poly(U)-directed poly(Phe) synthesis. Strain AZ27L was used to prepare an $\mathrm{S} 30$ extract containing $\mathrm{Sm}^{\mathrm{D}}$ ribosomes from which the endogenous EF-Tu was removed by immunoretention (Talens et al., 1996). Wild-type EF-Tu and EFTuA[375T] were purified as described by Mesters et al. (1994). EF-Tu[G222D] has a C-terminal Ser(His) ${ }_{6}$ extension, which enables purification by $\mathrm{Ni}^{2+}$-affinity chromatography (Boon et al., 1992). Purified EF-Tu was added to reaction mixtures $(50 \mu \mathrm{l})$ containing $8 \mu \mathrm{l} \mathrm{AZ27L} \mathrm{S30} \mathrm{extract,} 40 \mathrm{mM}$ Tris/ acetate, $\mathrm{pH} 7 \cdot 6,10 \mathrm{mM}$ magnesium acetate, $70 \mathrm{mM} \mathrm{NH}_{4} \mathrm{Cl}$, $1 \mathrm{mM}$ DTT, $5 \mathrm{mM}$ phosphoenolpyruvate, $2 \mathrm{mM} \mathrm{ATP}, 50 \mu \mathrm{M}$ GTP, $10 \mu \mathrm{g}$ pyruvate kinase $\mathrm{ml}^{-1}, 0 \cdot 4 \mathrm{mg}$ bulk tRNA (Sigma) $\mathrm{ml}^{-1}, 160 \mu \mathrm{g}$ poly(U) $\mathrm{ml}^{-1}$ (Boehringer) and $2 \mu \mathrm{l}{ }^{14} \mathrm{C}$-Phe $\left(50 \mu \mathrm{Ci} \mathrm{ml} l^{-1}, 150 \mathrm{mCi} \mathrm{mmol}^{-1}, 1 \mathrm{Ci}=3.7 \times 10^{10} \mathrm{~Bq}\right)(\mathrm{ICN})$. Reactions were incubated at $37^{\circ} \mathrm{C}$ for $10 \mathrm{~min}$ and stopped by the addition of $60 \mu \mathrm{l} 0 \cdot 1 \mathrm{M} \mathrm{NaOH}$ and further incubation at $37^{\circ} \mathrm{C}$ for $5 \mathrm{~min}$. Polypeptides were precipitated by the addition of $5 \%(\mathrm{w} / \mathrm{v})$ TCA and filtered on GF/C (Whatmann) filters. The amount of ${ }^{14} \mathrm{C}$-Phe incorporated into polypeptides was determined by liquid-scintillation counting. Representative results from at least two experiments are given in Figs $1-3$. The error range for the data points in Fig. 1 is up to $20 \%$ 
for the smaller values, in Fig. 2 up to $17 \%$ and in Fig. 3. up to $25 \%$ (see error bars).

\section{RESULTS}

\section{Identification of the $\mathrm{Sm}^{\mathrm{D}}$ mutation in strain UD666}

Although ribosomes isolated from E. coli strain UD666 (harbouring the rpsL666 allele) have been used to analyse the functional defects of the $\mathrm{Sm}^{\mathrm{D}} \mathrm{S} 12$ mutation (Ruusala et al., 1984), the mutation itself had not been identified. $\mathrm{Sm}^{\mathrm{D}}$ mutations are known to cluster around position 42 and 90 in S12 and ancillary mutations in S12 frequently occur. The latter do not always cause a distinct phenotype but some improve the growth rate (Timms \& Bridges, 1993).

The chromosomal $r p s L$ gene from the $S m^{D}$ strain UD666 was amplified by PCR and sequenced. A C $\rightarrow \mathrm{T}$ mutation was found, resulting in a change from proline to leucine at position 90 in the $S 12$ protein. The same mutation had already been described in an E. coli $\mathrm{B} / \mathrm{r}$ strain (Timms et al., 1992; GenBank accession no. 147892). Sequencing the whole $r p s L$ gene revealed no ancillary mutations.

\section{Reversion of streptomycin dependence by mutant EF- Tu}

In search of EF-Tu-specific suppressors of streptomycin dependence caused by mutations in S12, we used the technique of M13-mediated gene replacement to randomly mutagenize the tuf genes in the $\mathrm{Sm}^{\mathrm{D}}$ strain UD666, followed by selection for streptomycin independence. P1 phage transduction and M13 retrieval showed that the tufA gene was mutated and DNA sequence analysis revealed the A375T $\left(\mathrm{A}_{\mathbf{R}}\right)$ mutation in EF-Tu. This mutation had previously been identified as a kirromycin-resistant and error-prone mutation (Duisterwinkel et al., 1981; Bosch et al., 1996 and references therein). To exclude the possibility that suppression of streptomycin dependence was due to other mutation(s) in the M13 phage, strain UD666 was infected with an M13 lysate containing solely $t u f A_{\mathrm{R}}$. Again we found suppression of streptomycin dependence, indicating that EF-TuA $A_{R}$ is indeed responsible for reversion of the $\mathrm{Sm}^{\mathrm{D}}$ phenotype to an independent $\left(\mathrm{Sm}^{\mathrm{I}}\right)$ and even streptomycin-sensitive $\left(\mathrm{Sm}^{\mathrm{S}}\right)$ phenotype. Other kirromycin-resistant EF-Tu species, with mutations such as Q124K, also error-prone, G316D or A375V (Mesters et al., 1994), were not able to reverse the streptomycin dependence of strain UD666. Repeated attempts to suppress the $\mathrm{Sm}^{\mathrm{D}}$ phenotype of UD666 by introducing the A375T mutation in $t u f B$ were unsuccessful. This may be due to the lower expression from the tufB gene (van der Meide et al., 1982). We also tested whether other $\mathrm{Sm}^{\mathrm{D}} \mathrm{S} 12$ mutations could be suppressed by EF-TuA $A_{R}$. tuf $A_{R}$ was introduced using M13mediated allelic replacement in strains CM1234 and CM1243, containing the S12 mutations K42Q and P90R, respectively. In both cases the presence of EF-TuA reversed the $S \mathrm{~m}^{\mathrm{D}}$ phenotype to $\mathrm{Sm}^{\mathrm{I}}$. However, streptomycin dependence of strain AZ1 caused by the double mutation miaA/rpsL282 could not be suppressed by the $\mathrm{A}_{\mathbf{R}}$ mutation.

In $r p s L^{+}$strains kirromycin sensitivity is dominant over resistance (van de Klundert et al., 1978), but here the $S m^{\mathrm{I}}$ strain LZ18L (rpsL666 tuf $A_{\mathrm{R}}$ ) turned out to be kirromycin-resistant, despite the presence of wt EF$\mathrm{TuB}$. This phenomenon has already been observed in Salmonella typhimurium harbouring EF-Tu[A375T] and an error-restrictive $\mathrm{Sm}^{\mathrm{R}}$ mutation in $\mathrm{S} 12$ (Tubulekas et al., 1991).

\section{The effect of mutant EF-TuB species in the Sm' strain}

The $\mathrm{Sm}^{\mathrm{I}}$ strain LZ18L contains a mixed EF-Tu population, EF-TuA $A_{R}$ and wt EF-TuB $\left(B_{S}\right)$. This raised the question whether the combination of these two different EF-Tu species is needed for suppression of streptomycin dependence or whether EF-TuA $A_{R}$ alone would be sufficient. We therefore tried to isolate $\mathrm{Sm}^{\mathrm{I}}$ colonies after randomly mutagenizing $t u f A$ in an $\mathrm{Sm}^{\mathrm{D}}$ strain with

Table 2. Growth rate of strains harbouring mutations in rpsL, tufA and/or tufB

\begin{tabular}{|c|c|c|c|c|}
\hline Strain & Relevant genotype & $\begin{array}{c}\text { Relevant } \\
\text { phenotype }\end{array}$ & $\begin{array}{c}\text { Doubling time } \\
\text { (min) }\end{array}$ & $\begin{array}{c}\text { Relative doubling } \\
\text { time }(\%)\end{array}$ \\
\hline AZ25L & $r p s L 666 t u f A_{\mathrm{R}} t u f B_{\mathrm{S}}$ & $S m^{I}$ & $98 \pm 2$ & $1 \cdot 00$ \\
\hline AZ27L & $r p s L 666$ tuf $A_{\mathrm{R}}$ tufB $B_{\mathrm{R}}$ & $S \mathrm{~m}^{1}$ & $95 \pm 3$ & 0.97 \\
\hline AZ29L & rpsL666 tuf $A_{\mathrm{R}}$ tufB $\mathrm{B}_{0}$ & $\mathrm{Sm}^{\mathrm{I}}$ & $105 \pm 2$ & 1.07 \\
\hline AZ31L & rpsL666 tufA $A_{\mathrm{R}}$ tufB $:: \mathrm{Mu}$ & $\mathrm{Sm}^{\mathrm{I}}$ & $129 \pm 4$ & $1 \cdot 32$ \\
\hline PM816 & $r p s L^{+} t u f A_{\mathrm{R}} t u f B_{\mathrm{S}}$ & $\mathrm{Sm}^{\mathrm{s}}$ & $30^{*}$ & $1 \cdot 00$ \\
\hline - & $r p s L^{+} \operatorname{tufA_{\mathrm {R}}} t u f B_{\mathrm{R}}$ & $\mathrm{Sm}^{\mathrm{s}}$ & ND & - \\
\hline LBE2021 & $r p s L^{+} t u f A_{\mathrm{R}} t u f B_{0}$ & $S m^{\mathrm{s}}$ & $31^{*}$ & 1.03 \\
\hline PM455 & $r p s L^{+} t u f A_{\mathrm{R}}$ tufB: : $\mathrm{Mu}$ & $\mathrm{Sm}^{\mathrm{s}}$ & $28^{*}$ & 0.93 \\
\hline
\end{tabular}

ND, Not determined by Van der Meide et al. (1982).

*Values from van der Meide et al. (1982). 
an insertionally inactivated tufB (LZ50), but several attempts were unsuccessful. However, when an M13 lysate containing $t u f A_{\mathrm{R}}$ was used, an $\mathrm{Sm}^{\mathrm{I}}$ strain (LZ52L) was isolated, but only after long incubation $(72 \mathrm{~h})$ and with a low transduction frequency. Thus, EF-TuA alone is capable of suppressing streptomycin dependence, but not as well as when wt EF-TuB is present. Is this due to a reduced cellular concentration of EF-Tu in the cell or is a cooperative effect between EF-TuA $A_{R}$ and wt EF-TuB responsible for good complementation? To answer this question a series of isogenic strains was constructed, harbouring $r p s L 666$ tuf $A_{\mathrm{R}}$ and different alleles of $t u f B$. rpsL666 and tuf $A_{\mathrm{R}}$ were simultaneously transduced to strains LBE2041 $\left(\mathrm{A}_{\mathrm{S}} \mathrm{B}_{\mathrm{S}}\right)$, EV102 $\left(\mathrm{A}_{\mathrm{S}} \mathrm{B}_{\mathrm{R}}\right)$, LBE2020 $\left(A_{\mathrm{S}} \mathrm{B}_{0}\right)$ and PM505 $\left(\mathrm{A}_{\mathrm{S}} \mathrm{B}:: \mathrm{Mu}\right)$ because manipulating them separately proved to be difficult due to a $90 \%$ linkage between the two genes. It appeared that the resulting strains, AZ25L, AZ27L, AZ29L and AZ31L, easily generated revertants and we were very careful in selecting and checking colonies for further experiments. The nature of EF-TuA and EF-TuB in these strains was confirmed using a kirromycin bandshift assay. This assay is based on the difference in electrophoretic mobility under non-denaturing conditions of EF-Tu bound to kirromycin as compared to unbound EF-Tu. EF-TuA $A_{R}$ does not bind kirromycin because of its resistant character and can thus be distinguished from wt EF-Tu and EF-TuB $\mathrm{B}_{0}$ in this assay (data not shown). The presence of the P90L mutation in S12 of the various strains was confirmed by sequencing their $r p s L$ genes. This also showed that no ancillary mutations in $r p s L$ had occurred during the manipulation of these strains.

Growth rate measurements in rich medium clearly demonstrated that the combination of the two different EF-Tu species, $A_{R}$ and $B_{S}$, is not the only possibility for good reversion of streptomycin dependence (Table 2). The latter is also achieved when wt EF-TuB is replaced

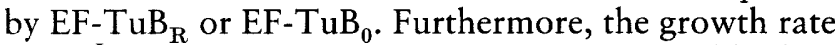
of $S m^{\mathrm{I}}$ rpsL666 tufA $A_{\mathrm{R}}$ strains is more susceptible than that of the corresponding $r p s L^{+}$strains to reduction in the EF-Tu concentration, since the generation time of strain $A Z 31 \mathrm{~L}$ carrying a $t u f B$ disruption is increased by about $30 \%$ (Table 2, compare strains AZ25L and $\mathrm{AZ31L}$ ). In $r p s L^{+}$strains this disruption does not lead to a reduction in growth rate in rich medium (Table 2, compare strains PM816 and PM455) (van der Meide et al., 1982).

\section{In vitro analysis of streptomycin dependence suppression by mutant EF-Tu species}

$\mathrm{EF}-\mathrm{Tu}[\mathrm{G} 222 \mathrm{D}]\left(\mathrm{B}_{0}\right)$ alone is not able to sustain in vitro protein synthesis with wt ribosomes. However, in vivo a positive effect of EF-Tu[G222D] on growth rate was observed in the presence of $\mathrm{Sm}^{\mathrm{D}}$ ribosomes and EF$\mathrm{Tu}[\mathrm{A} 375 \mathrm{~T}]$ (Table 2). We therefore also tested in vitro the ability of wt EF-Tu, EF-Tu[A375T] and EF$\mathrm{Tu}[\mathrm{G} 222 \mathrm{D}]$ to sustain protein synthesis in an EF-Tudepleted S30 extract of strain AZ27L containing $\mathrm{Sm}^{\mathrm{D}}$

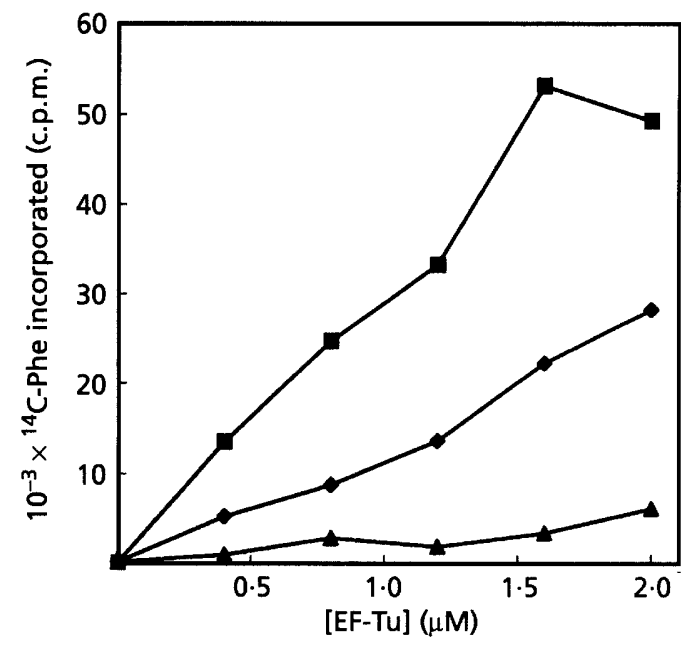

Fig. 1. Poly(U)-directed poly(Phe) synthesis with different EF-Tu species and $\mathrm{Sm}^{\mathrm{D}}$ ribosomes. Purified wt EF-Tu $(\diamond)$, EF-Tu[A375T] (E) or EF-Tu[G222D] (A) were added at the indicated concentrations to an EF-Tu-depleted S30 extract of AZ27L and their translational activity was measured. For further experimental details, see Methods.

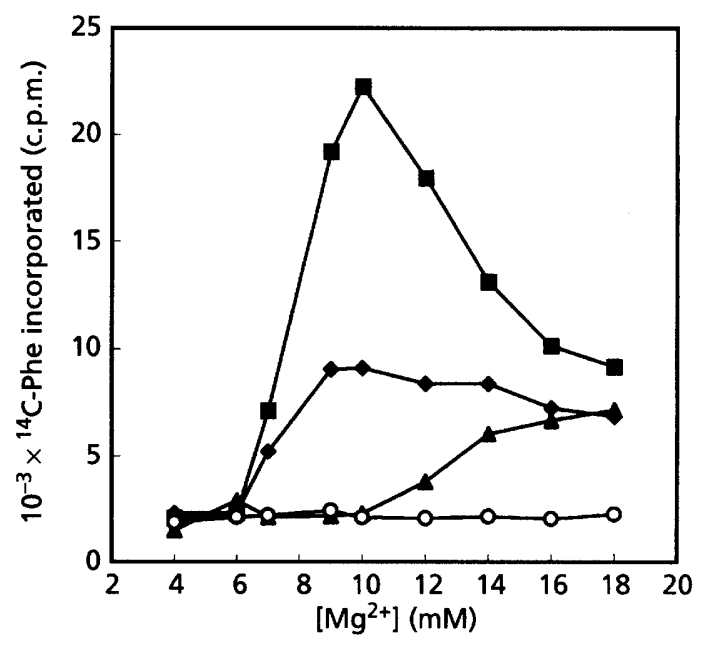

Fig. 2. Poly(U)-directed poly(Phe) synthesis with $\mathrm{Sm}^{\mathrm{D}}$ ribosomes as a function of $\mathrm{Mg}^{2+}$ concentration. Activity in poly(Phe) synthesis of $0.5 \mu \mathrm{M}$ wt EF-Tu ( $\bullet), 0.5 \mu \mathrm{M}$ EF-Tu[A375T] ( $\square$ ), $0.5 \mu \mathrm{M}$ EF-Tu[G222D] $(\Delta)$ or no EF-Tu $(O)$ was measured as described in Methods.

ribosomes (Fig. 1). In the absence of streptomycin, wt EF-Tu is still active in the poly(Phe) synthesis assay, but about $60 \%$ less so than EF-Tu[A375T], while EF$\mathrm{Tu}$ [G222D] is not active at all. Furthermore, the activities of wt EF-Tu and EF-Tu[A375T] appear to be

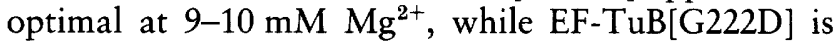
weakly active only at non-physiological $\mathrm{Mg}^{2+}$ concentrations of $14 \mathrm{mM}$ and higher (Fig. 2). Thus, EF$\mathrm{Tu}[\mathrm{G} 222 \mathrm{D}]$ alone is not likely to productively interact with $\mathrm{Sm}^{\mathrm{D}}$ ribosomes in vivo. 


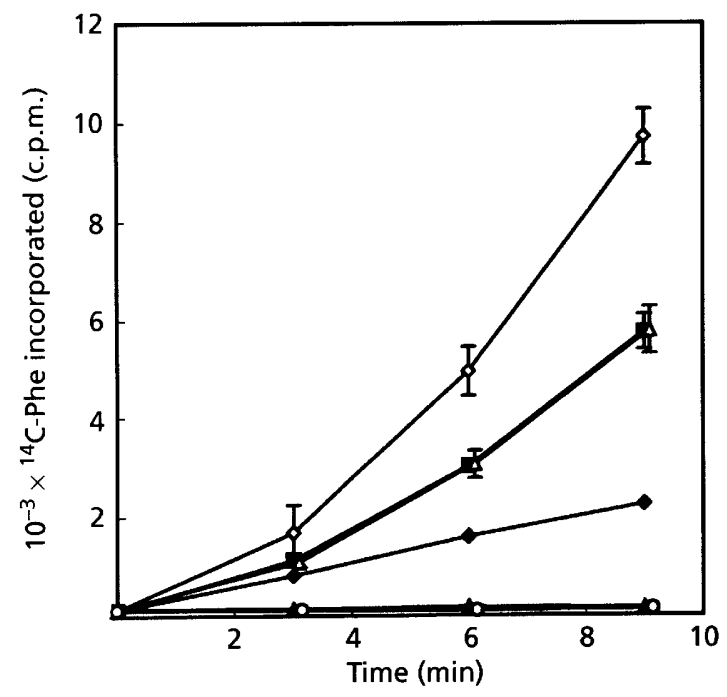

Fig. 3. Poly(U)-directed poly(Phe) synthesis with $\mathrm{Sm}^{\mathrm{D}}$ ribosomes and EF-Tu ${ }_{R}$ and the stimulation by other EF-Tu species. Activity in poly(Phe) synthesis of $0.3 \mu \mathrm{M}$ wt EF-Tu $(\diamond), 0.3 \mu \mathrm{M}$ EF$\mathrm{Tu}[\mathrm{G} 222 \mathrm{D}]$ (A), $0.3 \mu \mathrm{M}$ EF-Tu[A375T] (G), no EF-Tu (O) or combinations of $0.3 \mu \mathrm{M}$ wt EF-Tu/0.3 $\mu \mathrm{M}$ EF-Tu[A375T] $(\diamond)$ and $0.3 \mu \mathrm{M}$ EF-Tu[G222D]/0.3 $\mu \mathrm{M}$ EF-Tu[A375T] $(\triangle)$ was measured as a function of time by using the reaction mixtures and incubations as described in Methods. Error bars are given for two independent measurements.

Synergism between EF-Tu[A375T] and EF-Tu[G222D] could be another explanation for our in vivo results, since such an effect had already been observed in vivo for their joint stimulation of read-through and frameshifting. To examine this possibility we analysed the activities of wt EF-Tu or EF-Tu[G222D] in combination with EF-Tu[A375T] and the isolated activities in the poly(Phe) synthesis assay with $S \mathrm{~m}^{\mathrm{D}}$ ribosomes at $10 \mathrm{mM}$ $\mathrm{Mg}^{2+}$. No synergistic effect could be observed when either wt EF-Tu or EF-Tu[G222D] was added to EF$\mathrm{Tu}[\mathrm{A} 375 \mathrm{~T}]$ in the reaction mixture (Fig. 3). In the latter combination we found exactly the same activity as for $\mathrm{EF}-\mathrm{Tu}[\mathrm{A} 375 \mathrm{~T}]$ alone.

\section{DISCUSSION}

\section{Reversion of streptomycin dependence}

Streptomycin dependence caused by mutations in ribosomal protein $\mathrm{S} 12$ can be complemented by ram mutations in ribosomal proteins S4 and S5, and in 16S rRNA (Birge \& Kurland, 1970; Deusser et al., 1970; Allen \& Noller, 1991; Lodmell \& Dahlberg, 1997). Here we have shown that the kirromycin-resistant and errorprone EF-Tu with mutation $\mathrm{A} 375 \mathrm{~T}\left(\mathrm{EF}-\mathrm{TuA} \mathrm{A}_{\mathrm{R}}\right)$ is also able to complement the $\mathrm{Sm}^{\mathrm{D}}$ phenotype of different $\mathrm{S} 12$ mutations. However, this is not a general property of kirromycin-resistant EF-Tus, since suppression of streptomycin dependence by $\mathrm{EF}-\mathrm{Tu}[\mathrm{Q} 124 \mathrm{~K}]$ or $\mathrm{EF}$ $\mathrm{Tu}[\mathrm{G} 316 \mathrm{D}]$ could not be demonstrated. Furthermore,
$\mathrm{EF}-\mathrm{Tu}[\mathrm{A} 375 \mathrm{~T}]$ is not able to reverse streptomycin dependence caused by the double mutation miaA/ rpsL282, suggesting that this double mutation belongs to a class of $\mathrm{Sm}^{\mathrm{D}}$ mutations different from the abovementioned S12 mutations. A subdivision of $\mathrm{Sm}^{\mathrm{D}}$ mutations was reported by Bjare \& Gorini (1971).

Recently, it became evident that a conformational switch in the 912 region of $16 \mathrm{~S}$ rRNA is involved in translational fidelity (Lodmell \& Dahlberg, 1997). The two alternating base-paired arrangements produce either an error-prone or a restrictive state. Restrictive mutations in this switch region are compatible with ram mutations in S5. On the other hand, error-prone mutations in the switch region are compatible with restrictive mutations in S12. Ribosomal proteins S5 and S12 are probably in close contact with the 912 region and facilitate switching between the two conformations. The EF-Tu binding site on the ribosome is in the proximity of $\mathrm{S} 12$ and not far from the 912 region. Our findings therefore fit the model by assuming that the error-prone character of the A375T mutation in EF-Tu disturbs switching between the two conformers (either directly or via S12) at a certain stage during initial codon-anticodon recognition or proofreading, and that this is counteracted by a restrictive mutation in S12. The kirromycin-resistant and also error-prone EF$\mathrm{Tu}[\mathrm{Q} 124 \mathrm{~K}]$ mutation (previously described as EFTuA*; Vijgenboom \& Bosch, 1989) did not reverse streptomycin dependence. Thus, suppression of the $\mathrm{Sm}^{\mathrm{D}}$ phenotype is not simply a matter of balancing translational accuracy, but probably requires specific interactions between EF-Tu and S12. Codons 40-43 and $87-90$ in $\mathrm{S} 12$ are known to be hot spots for $\mathrm{Sm}^{\mathrm{D}}$ mutations (Timms et al., 1992). We found that not only strains harbouring the $\mathrm{Sm}^{\mathrm{D}}$ mutation $\mathrm{P} 90 \mathrm{~L}$, but also strains harbouring the $\mathrm{Sm}^{\mathrm{D}}$ mutations $\mathrm{P} 90 \mathrm{R}$ or $\mathrm{K} 42 \mathrm{Q}$ become $\mathrm{Sm}^{\mathrm{I}}$ after expression of EF-TuA $\mathrm{R}_{\mathrm{R}}$. Unfortunately, the three-dimensional structure of $S 12$ is not known, but one could imagine that positions 42 and 90 are in close proximity as part of a contact area controlling translational accuracy.

Strains carrying both the $S m^{\mathrm{D}} r p s L 666$ and the $t u f A_{\mathrm{R}}$ mutations show a reversion to streptomycin sensitivity. In addition, these strains have become kirromycinresistant although sensitive wt EF-Tu is present. Such a dominant kirromycin-resistant phenotype, together with a reduced resistance to streptomycin, has also been described for an S. typhimurium strain harbouring an error-restrictive $\mathrm{Sm}^{\mathrm{R}} \mathrm{S} 12$ mutation in combination with the EF-Tu[A375T] mutation (Tubulekas et al., 1991). For these hyperaccurate ribosomes it has been shown that they preferentially use EF-Tu[A375T] for translation. The same may also be true for $\mathrm{Sm}^{\mathrm{D}}$ ribosomes, because under non-saturating conditions EF-Tu[A375T] is 2.5 -fold more active in poly (Phe) synthesis than wt EFTu when these ribosomes are used. On the other hand, we previously reported that EF-Tu[A375T] is threefold less active than wt EF-Tu with wt ribosomes (Talens $e t$ al., 1996). 


\section{Cell growth enhancement by EF-TuB}

Although EF-TuA $A_{R}$ suppresses the $S m^{D}$ phenotype of strain UD666, the generation time of $\mathrm{Sm}^{\mathrm{I}}$ strains is always three- to fourfold longer than that of the corresponding $r p s L^{+}$strain, indicating that not all defects caused by the $S 12$ mutation can be complemented by EF-TuA $A_{R}$. Furthermore, the expression of wt EF-Tu, $E F-T u B_{R}$, or $E F-T u B_{0}$ from a tufB allele in strains harbouring rpsL666 tuf $A_{\mathrm{R}}$ (AZ25L, AZ27L and AZ29L, respectively) increased the growth rate to the same extent when compared to the isogenic strain lacking EF$\mathrm{TuB}(\mathrm{AZ} 31 \mathrm{~L})$. An explanation could be that the presence of wt EF-TuB is already sufficient for maximal suppression of the $\mathrm{Sm}^{\mathrm{D}}$ phenotype in vivo, although less effective at limiting concentrations in sustaining poly(Phe) synthesis with $\mathrm{Sm}^{\mathrm{D}}$ ribosomes than EF$\mathrm{Tu}[\mathrm{A} 375 \mathrm{~T}]$. In vitro, we observe an additive effect of wt $\mathrm{EF}-\mathrm{Tu}$ on protein synthesis with $\mathrm{Sm}^{\mathrm{D}}$ ribosomes in combination with EF-Tu[A375T] which might account for the increased growth rate of such a strain in comparison to a tufB::Mu strain.

The result with EF-TuB ${ }_{0}$ is more puzzling because this mutant EF-Tu species is not active in protein synthesis with wt ribosomes. The main effect of the G222D mutation is an inhibition of the signal transmission to the GTPase centre of EF-Tu triggered by codon-induced conformational transitions of the tRNA (Vorstenbosch et al., 1996). Normally, the transmission leads to GTP hydrolysis and further steps of A-site binding. This inhibition can be overcome by increasing the amount of $\mathrm{Mg}^{2+}$. We tested whether EF-Tu[G222D] would have a better functional interaction with $\mathrm{Sm}^{\mathrm{D}}$ ribosomes, but, just as with wt ribosomes, EF-Tu[G222D] was inactive in poly(Phe) synthesis at physiological $\mathrm{Mg}^{2+}$ concentrations $(5-9 \mathrm{mM})$ and became active only at higher $\mathrm{Mg}^{2+}$ concentrations. The effect on the growth rate could also be due to a sort of synergism between EF$\mathrm{Tu}[\mathrm{A} 375 \mathrm{~T}]$ and EF-Tu[G222D] as reported for in vivo suppression of nonsense and frameshift mutations (Vijgenboom et al., 1985; Vijgenboom \& Bosch, 1989). However, under our in vitro conditions no such synergistic contribution of EF-Tu[G222D] to protein synthesis could be detected.

Therefore, the positive contribution of $\mathrm{EF}^{-\mathrm{TuB}_{0}}$ in suppressing streptomycin dependence together with EF$T u A_{R}$ as seen in growth-rate experiments, awaits further explanation. In cells with active tufA and tufB, the EF$\mathrm{Tu} / \mathrm{aa}-\mathrm{tRNA}$ ratio is about $1: 1$ and complex formation is advantageous for the protection of the labile aminoacyl ester bond against unwanted hydrolysis. EF$\mathrm{TuB}_{0}$ is not disturbed in ternary complex formation and thus protects a certain amount of aa-tRNA in the cell from spontaneous deacylation. It cannot deliver the aatRNA to the ribosomal A-site, but it could perhaps act as a supplier of aa-tRNA to EF-Tu species which are active in protein synthesis, if we assume that a rapid transfer of aa-tRNA from EF-TuB ${ }_{0} \cdot G T P \cdot a a-t R N A$ to, for example EF-TuA $A_{R} \cdot G T P$, is possible. This might then explain the positive contribution of EF-TuB to suppression of streptomycin dependence as compared to strains lacking EF-TuB.

The abundance of EF-Tu in fast-growing cells (8-10 copies per ribosome) has promoted searches for other roles for EF-Tu. Several groups have speculated about an additional role connected to the reported additional round of GTP hydrolysis per peptide bond formation (Weijland \& Parmeggiani, 1993; Ehrenberg et al., 1993; Bosch et al., 1996). Recently, a chaperone-like refolding activity was reported for EF-Tu (Kudlicki et al., 1997). The positive contribution of the defective EF-TuB ${ }_{0}$ to the $\mathrm{Sm}^{\mathrm{I}}$ phenotype described in this paper could well be understood from its participation, just like wt EF-Tu, in such an additional and vital role.

\section{ACKNOWLEDGEMENTS}

We thank Professor L. Bosch (Leiden University) and Dr D. Hughes (Uppsala University) for their interest and for critical reading of the manuscript. This work is supported by the Netherlands Foundation for Chemical Research (SON 328035 ) with financial aid from the Netherlands Organization for Scientific Research (NWO).

\section{REFERENCES}

Allen, P. N. \& Noller, H. F. (1991). A single base substitution in $16 \mathrm{~S}$ ribosomal RNA suppresses streptomycin dependence and increases the frequency of translational errors. Cell 66, 141-148.

Anborgh, P. H. \& Parmeggiani, A. (1991). New antibiotic that acts specifically on the GTP-bound form of elongation factor Tu. EMBO J 10, 779-784.

Andersson, D. I., Andersson, S. G. E. \& Kurland, C. G. (1986). Functional interactions between mutated forms of ribosomal proteins S4, S5 and S12. Biochimie 68, 705-713.

Bilgin, N. \& Ehrenberg, M. (1994). Mutations in $23 S$ ribosomal RNA perturb transfer RNA selection and can lead to streptomycin dependence. J Mol Biol 235, 813-824.

Bilgin, N., Claesens, F., Phaverk, H. \& Ehrenberg, M. (1992). Kinetic properties of Escherichia coli ribosomes with altered forms of S12. J Mol Biol 224, 1011-1027.

Birge, E. A. \& Kurland, C. G. (1969). Altered ribosomal protein in streptomycin-dependent Escherichia coli. Science 166, 1282-1284.

Birge, E. A. \& Kurland, C. G. (1970). Reversion of a streptomycindependent strain of Escherichia coli. Mol Gen Genet 109, 356-369.

Bjare, U. \& Gorini, L. (1971). Drug dependence reversed by a ribosomal ambiguity mutation, ram, in Escherichia coli. $\mathrm{J} \mathrm{Mol}$ Biol 57, 423-435.

Boon, K., Vijgenboom, E., Madsen, L. V., Talens, A., Kraal, B. \& Bosch, L. (1992). Isolation and functional analysis of histidinetagged elongation factor Tu. Eur J Biochem 210, 177-183.

Bosch, L., Vijgenboom, E. \& Zeef, L. A. H. (1996). A revised bacterial polypeptide chain elongation cycle with a stepwise increase in restriction of unwanted ternary complexes by the ribosome. Biochemistry 35, 12647-12651.

Dean, D. (1981). A plasmid cloning vector for the direct selection of strains carrying recombinant plasmids. Gene 15, 99-102.

Deusser, E., Stöffler, G., Wittman, H. G. \& Apirion, G. (1970). Altered S4 proteins in Escherichia coli revertants from streptomycin dependence to independence. Mol Gen Genet 109, $298-302$. 
Duisterwinkel, F. J., de Graaf, J. M., Kraal, B. \& Bosch, L. (1981). A kirromycin resistant elongation factor EF-Tu from Escherichia coli contains a threonine instead of an alanine in position 375 . FEBS Lett 131, 89-93.

Duisterwinkel, F. J., Kraal, B., de Graaf, J. M., Talens, A., Bosch, L., Swart, G. W. M., Parmeggiani, A., La Cour, T. F. M., Nyborg, J. \& Clark, B. F. C. (1984). Specific alterations of the EF-Tu polypeptide chain considered in the light of its three-dimensional structure. EMBO J 3, 113-120.

Ehrenberg, M., Bilgin, N. \& Scoble, J. (1993). EF-Tu stochiometries in code translation. In The Translational Apparatus: Structure, Function, Regulation, Evolution, pp. 305-315. Edited by K. H. Nierhaus, F. Franceschi, A. R. Subramanian, V. A. Erdmann \& B. Wittmann-Liebold. New York: Plenum.

Faxén, M., Kirsebom, L. A. \& Isaksson, L. A. (1988). Is efficiency of suppressor tRNAs controlled at the level of ribosomal proofreading in vivo? J Bacteriol 170, 3756-3760.

Hughes, D., Atkins, J. F. \& Thompson, S. (1987). Mutants of elongation factor $\mathrm{Tu}$ promote ribosomal frameshifting and nonsense readthrough. EMBO J 6, 4235-4239.

Kudlicki, W., Coffman, A., Kramer, G. \& Hardesty, B. (1997). Renaturation of rhodanese by translational elongation factor (EF) Tu. J Biol Chem 272, 32206-32210.

Lodmell, J. S. \& Dahlberg, A. E. (1997). A conformational switch in Escherichia coli $16 \mathrm{~S}$ ribosomal RNA during decoding of messenger RNA. Science 277, 1262-1267.

Mesters, J. R., Zeef, L. A. H., Hilgenfeld, R., de Graaf, J. M., Kraal, B. \& Bosch, L. (1994). The structural and functional basis for the kirromycin resistance of mutant EF-Tu species in Escherichia coli. EMBO J 13, 4877-4885.

Miller, D. L. \& Weissbach, H. (1977). Factors involved in the transfer of aminoacyl-tRNA to the ribosome. In Molecular Mechanisms of Protein Biosynthesis, pp. 323-372. Edited by $\mathrm{H}$. Weissbach \& S. Pestka. New York: Academic Press.

Miller, J. H. (1972). Experiments in Molecular Genetics. Cold Spring Harbor, NY: Cold Spring Harbor Laboratory.

O'Connor, M., De Stasio, E. A. \& Dahlberg, A. E. (1991). Interaction between $16 \mathrm{~S}$ ribosomal RNA and ribosomal protein S12: differential effects of paromomycin and streptomycin. Biochimie 73, 1493-1500.

Ozaki, M., Mizushima, S. \& Nomura, M. (1969). Identification and functional characterization of the protein controlled by the streptomycin-resistant locus in E. coli. Nature 222, 333-339.

Petrullo, L. A., Gallagher, P. J. \& Elseviers, D. (1983). The role of 2-methylthio-N6-isopentenyladenosine in readthrough and suppression of nonsense codons in Escherichia coli. Mol Gen Genet 190, 289-294.

Powers, T. \& Noller, H. F. (1991). A functional pseudoknot in $16 \mathrm{~S}$ ribosomal RNA. EMBO J 10, 2203-2214.

Ruusala, T., Andersson, D., Ehrenberg, M. \& Kurland, C. G. (1984). Hyper-accurate ribosomes inhibit growth. EMBO J 3, 2575-2580.

Saarma, U., Remme, J., Ehrenberg, M. \& Bilgin, N. (1997). An A to $\mathrm{U}$ transversion at position 1067 of $23 \mathrm{~S}$ rRNA from Escherichia coli impairs EF-Tu and EF-G function. J Mol Biol 272, 327-335.

Spickler, C., Brunelle, M.-N. \& Brakier-Gringas, L. (1997). Streptomycin binds to the decoding center of $16 \mathrm{~S}$ ribosomal RNA. J Mol Biol 273, 586-599.

Stark, H., Rodnina, M. V., Rinke-Appel, J., Brimacombe, R., Wintermeyer, W. \& van Heel, M. (1997). Visualization of elongation factor Tu on the Escherichia coli ribosome. Nature $389,403-406$.
Swart, G. W. M., Parmeggiani, A., Kraal, B. \& Bosch, L. (1987). Effects of the mutation glycine-222 $\rightarrow$ aspartic acid on the functions of elongation factor Tu. Biochemistry 26, 2047-2054.

Talens, A., Boon, K., Kraal, B. \& Bosch, L. (1996). Translational activities of EF-Tu[G222D] which cannot be reconciled with the classical scheme of the polypeptide chain elongation cycle. Biochem Biophys Res Commun 225, 961-967.

Tapio, S. \& Isaksson, L. A. (1988). Antagonistic effects of mutant elongation factor $\mathrm{Tu}$ and ribosomal protein $\mathrm{S} 12$ on control of translation accuracy, suppression and cellular growth. Biochimie 70, 273-281.

Timms, A. R. \& Bridges, B. A. (1993). Double, independent mutational events in the $r p s L$ gene of Escherichia coli: an example of hypermutability? Mol Microbiol 9, 335-342.

Timms, A. R., Steingrimsdottir, H., Lehmann, A. R. \& Bridges, B. A. (1992). Mutant sequences in the rpsL gene of Escherichia coli $\mathrm{B} / \mathrm{r}$ : mechanistic implications for spontaneous and ultraviolet light mutagenesis. Mol Gen Genet 232, 89-96.

Tubulekas, I. \& Hughes, D. (1993). Suppression of $r p s L$ phenotypes by $t u f$ mutations reveals a unique relationship between translation elongation and growth rate. Mol Microbiol 7, 275-284.

Tubulekas, I., Buckingham, R. H. \& Hughes, D. (1991). Mutant ribosomes can generate dominant kirromycin resistance. $J$ Bacteriol 173, 3635-3643.

Van de Klundert, J. A. M., van der Meide, P. H., van der Putte, P. \& Bosch, L. (1978). Mutants of Escherichia coli altered in both genes coding for the elongation factor Tu. Proc Natl Acad Sci USA 75, 4470-4473.

Van der Meide, P. H. \& Vijgenboom, E. (1981). The effect of kirromycin on two mutant species of the elongation factor Tu. Eur J Biochem 117, 1-6.

Van der Meide, P. H., Vijgenboom, E., Dicke, M. \& Bosch, L. (1982). Regulation of the expression of $t u f A$ and $t u f B$, the two genes coding for the elongation factor EF-Tu in Escherichia coli. FEBS Lett 139, 325-330.

Vijgenboom, E. \& Bosch, L. (1987). Transfer of plasmid-borne $t u f$ mutations to the chromosome as a genetic tool for studying the functioning of EF-TuA and EF-TuB in the E. coli cell. Biochimie 69, 1021-1030.

Vijgenboom, E. \& Bosch, L. (1989). Translational frameshifts induced by mutant species of the polypeptide chain elongation factor Tu of Escherichia coli. J Biol Chem 264, 13012-13017.

Vijgenboom, E., Vink, T., Kraal, B. \& Bosch, L. (1985). Mutants of the elongation factor, a new class of nonsense suppressors. EMBO J 4, 1049-1052.

Vorstenbosch, E., Pape, T., Rodnina, M. V., Kraal, B. \& Wintermeyer, W. (1996). The G222D mutation in elongation factor $\mathrm{Tu}$ inhibits the codon-induced conformational changes leading to GTPase activation on the ribosome. EMBO J $\mathbf{1 5}$, 6766-6774.

Weijland, A. \& Parmeggiani, A. (1993). Toward a model for the interaction between elongation factor $\mathrm{Tu}$ and the ribosome. Science 259, 1311-1314.

Zeef, L. A. H. \& Bosch, L. (1993). A technique for targeted mutagenesis of the EF-Tu chromosomal gene by M13-mediated gene replacement. Mol Gen Genet 238, 252-260.

Received 24 April 1998; revised 11 August 1998; accepted 20 August 1998. 